\title{
Personality of outpatients with malignant tumors: a cross-sectional study
}

\author{
Zhuo Wang, Toshihiko Sakakibara and Yuichi Kasai ${ }^{*}$
}

\begin{abstract}
Background: There have been scarce large-scale studies investigating the personality of patients with malignant tumors. The purpose of this study is to determine the characteristic personality in malignant tumors outpatients.

Methods: Three thousand and three among 5013 consecutive outpatients who consented to answer the Japanese Maudsley Personality Inventory questionnaires were divided into two groups. 603 outpatients diagnosed with malignant tumors (M group) and the other 2400 outpatients (non-M group) were enrolled in this study. We determined three scores such as introversion/extroversion (E-score), neuroticism ( $\mathrm{N}$-score), and lie detection (L-score). All data were used to compare the two groups.

Results: Average E-score was slightly higher, and average $\mathrm{N}$-score was slightly lower in M group than that in non-M group, and no significant differences between the two groups. However, the average L-score in M group was significant higher than that in non-M group $(p<0.01)$.

Conclusion: Outpatients with malignant tumors showed a significantly higher L-score on MPI when compared with patients with non-malignant tumors. These results stress the importance of taking the mentality of patients with cancer into consideration when conducting treatment and care.
\end{abstract}

Keywords: Cancer, Personality, Extroversion, Neuroticism, Psychology

\section{Background}

It has been suggested that the personality of patients with malignant tumors may have an effect on tumor development or progression [1-3], and although various studies on this topic have been conducted, large-scale studies have been scarce. Therefore, in this study we conducted a personality inventory in approximately 3,000 outpatients who visited the diagnostic and treatment departments of our university hospital and compared the personality of patients with malignant tumors to the personality of patients with non-malignant tumors.

\section{Methods}

Of 5,013 outpatients who visited the diagnostic and treatment departments of our university hospital between January 24 and January 28, 2011, 3,055 patients (collection rate, $60.9 \%$ ) provided valid answers on the

\footnotetext{
*Correspondence: ykasai@clin.medic.mie-u.ac.jp

Department of Spinal Surgery and Medical Engineering, Mie University Graduate School of Medicine, 2-174 Edobashi, Tsu city, Mie 514-8507, Japan
}

personality inventory. Of these, 3,003 patients aged 20 years or older were included in the analyses.

The personality inventory used was the Japanese version of the Maudsley Personality Inventory (MPI), which was first published in English by Jensen in 1958 [4]. MPI comprises 80 items assessing three personality fields: introversion/extroversion, neurotic tendencies, and lying tendencies. In this inventory, introversion/extroversion score (E-score) is evaluated on a 48-point scale, neurotic tendency score ( $\mathrm{N}$-score) on a 48-point scale, and lying tendencies score (L-score) on a 40-point scale. As shown in Table 1, a higher E-score indicates greater extroversion; a higher $\mathrm{N}$-score indicates a greater neurotic tendency; and a higher L-score indicates a greater lying or exhibitionistic tendency $[5,6]$. This study was conducted after obtaining approval from the ethics committee of our university (approval no. 1143) and information regarding patient age, sex, and the department visited (multiple answers were allowed) were obtained while protecting patient anonymity. In our hospital, the disease name, such as cancer or malignant tumor, was in principle told to the
C Biomed Central (c) 2012 Wang et al.; licensee BioMed Central Ltd. This is an Open Access article distributed under the terms of the Creative Commons Attribution License (http://creativecommons.org/licenses/by/2.0), which permits unrestricted use, distribution, and reproduction in any medium, provided the original work is properly cited. 


\begin{tabular}{|c|c|c|}
\hline Score & Scale (point) & Judgment \\
\hline \multirow[t]{5}{*}{ E score } & $0-9$ & extreme introversion \\
\hline & $10-20$ & slight introversion \\
\hline & $21-31$ & average \\
\hline & $32-41$ & slight extroversion \\
\hline & $42-48$ & extreme extroversion \\
\hline \multirow[t]{5}{*}{ N score } & $0-8$ & scarce neurotic tendency \\
\hline & $9-18$ & low neurotic tendency \\
\hline & $19-28$ & average \\
\hline & 29-38 & neurotic tendency \\
\hline & $39-48$ & high neurotic tendency \\
\hline \multirow[t]{2}{*}{ L score } & $0-25$ & normal \\
\hline & $26-40$ & frequent lying and exhibitionistic tendency \\
\hline
\end{tabular}

patients themselves, and whether they were currently visiting our hospital due to a malignant tumor was answered by "Yes" or "No".

Of the 3,003 patients investigated in this study, 1,193 were men and 1,810 were women, and the mean age was $63.1 \pm 9.5$ years. There were 603 patients in the malignant tumor group ( $\mathrm{M}$ group) and 2,400 patients in the non-malignant tumor group (non- $M$ group). The mean age of the $M$ group was $65.3 \pm 12.3$ years and that of the non- $M$ group was $62.4 \pm 10.5$ years; thus, the $M$ group was slightly older, but there was no significant difference between the groups. With regard to sex, the M group included 255 men and 348 women, whereas the non-M group included 938 men and 1,462 women, showing no significant sex differences between the groups. The numbers of patients in both groups who visited each department (multiple answers allowed) are shown in Table 2. Because our hospital is a university hospital that conducts advanced treatments, fewer patients with endstage cancer received palliative care alone and more patients with cancer were being treated aggressively.

The checkpoints were E-, N-, and L-scores, which were compared between the $\mathrm{M}$ group and non-M group. Patient age was classified into three age groups, 20-49 years, 50-69 years, and 70 years or older, and the $\mathrm{E}-, \mathrm{N}-$, and L-scores of the $\mathrm{M}$ group and non-M group in each age group were compared. The patients were also divided into two groups by sex and the E-, N-, and $\mathrm{L}$-scores in the $\mathrm{M}$ group and non- $\mathrm{M}$ group were also compared between men and women. Student's t-test was used for statistical analysis and $\mathrm{p}<0.05$ was considered to indicate a significant difference.

\section{Results}

Average E-score was $27.5 \pm 11.6$ points in the $\mathrm{M}$ group and $26.6 \pm 11.8$ points in the non-M group, indicating
Table 2 Number of patients presenting to each department

\begin{tabular}{lcc}
\hline Hospital department & \multicolumn{2}{c}{ Number of patients } \\
\cline { 2 - 3 } & M-group & Non-M-group \\
\hline Family medicine & 2 & 60 \\
\hline Cardiology & 8 & 129 \\
\hline Oncology & 35 & 49 \\
\hline Diabetes, metabolism, and endocrinology & 16 & 120 \\
\hline Neurology & 6 & 80 \\
\hline Nephrology & 0 & 42 \\
\hline Haematology & 28 & 50 \\
\hline Gastroenterology and hepatology & 44 & 137 \\
\hline Respiratory medicine & 18 & 112 \\
\hline Gastrointestinal surgery & 22 & 64 \\
\hline Hepatobiliary pancreatic surgery & 14 & 56 \\
\hline Cardiovascular surgery & 2 & 64 \\
\hline Neurosurgery & 6 & 86 \\
\hline Oral and maxillofacial surgery & 24 & 160 \\
\hline Thoracic surgery & 14 & 20 \\
\hline Breast surgery & 82 & 90 \\
\hline Orthopaedic surgery & 44 & 184 \\
\hline Otorhinolaryngology & 32 & 146 \\
\hline Nephro-urologic surgery & 48 & 102 \\
\hline Obstetrics and gynaecology & 78 & 145 \\
\hline Ophthalmology & 14 & 260 \\
\hline Dermatology & 30 & 162 \\
\hline Radiology & 1 & 29 \\
\hline Pain clinic & 4 & 26 \\
\hline Others & 14 \\
\hline
\end{tabular}

that patients in the $M$ group were slightly more extroverted than those in the non- $M$ group, although this difference was not significant. Average N-score was $16.8 \pm 11.5$ points in the $M$ group and $17.7 \pm 12.2$ points the non- $M$ group, indicating that patients in the $M$ group had a slightly lower neurotic tendency than those in the non-M group; however, again, this difference was not significant. Average L-score was $17.6 \pm 7.0$ points in the $M$ group, significantly higher than that in the non- $M$ group $(16.8 \pm 7.4$ points; $\mathrm{p}<0.01)$, suggesting that more of the patients in the $M$ group had lying or exhibitionistic tendencies. Investigation by age and sex revealed no significant differences in E-, N-, and L-scores between the $\mathrm{M}$ group and the non-M group (Tables 3 and 4).

\section{Discussion}

The possibility that personality may be a risk factor for the development of malignant tumors has been suggested $[2,7,8]$. Eysenck et al. [2] mentioned that personality, rather than smoking, may be strongly associated with the development of lung cancer. Temoshok et al. [8], 
Table 3 Age of patients and scores in malignant group (M group) and non-malignant group (non-M group)

\begin{tabular}{|c|c|c|c|c|c|c|}
\hline \multirow[t]{2}{*}{ Age of patients (years) } & \multicolumn{3}{|c|}{$M$ group $(n=603)$} & \multicolumn{3}{|c|}{ Non-M group $(n=2400)$} \\
\hline & E-score & N-score & L-score & E-score & N-score & L-score \\
\hline $20-49$ & $27.3 \pm 13.1$ & $17.5 \pm 11.6$ & $17.7 \pm 6.4$ & $26.5 \pm 12.1$ & $18.4 \pm 13.0$ & $16.4 \pm 6.6$ \\
\hline $50-69$ & $27.1 \pm 11.0$ & $16.5 \pm 11.2$ & $17.1 \pm 5.8$ & $26.3 \pm 12.4$ & $17.4 \pm 12.4$ & $16.4 \pm 6.8$ \\
\hline 70- & $28.0 \pm 11.7$ & $16.3 \pm 11.5$ & $18.0 \pm 7.0$ & $27.1 \pm 11.3$ & $17.2 \pm 11.3$ & $17.7 \pm 6.9$ \\
\hline
\end{tabular}

No significant differences between the two groups.

reported that persons who tend to inhibit feelings such as anger or fear and make an effort to give a healthy impression may be more likely to develop malignant melanoma. However, the results of a few large cohort prospective study revealed that personality has no association with the development of cancer [9-11]. It had also been reported that personality may influence the progression or mortality of malignant tumors via action on the immune or endocrine systems [12]. However, the results of recent prospective studies by Nakaya et al. suggest that psychological elements do not significantly influence the progression or mortality of cancer $[13,14]$.

Although personality is considered to have little influence on the development, progression, or mortality of malignant tumors, personality is strongly associated with the quality of life of patients [15]. Thus, it is very important for health professionals to assess the personality of patients with malignant tumors. Because few studies have investigated the personality of patients with malignant tumors, the data from the present study are expected to be of value.

With regard to the extroversion/introversion and neurotic tendencies of patients with malignant tumors, Kisen et al. [16] reported that male patients with lung cancer tended to be extroverted with a low neurotic tendency. Furthermore, Coppen et al. [17] found that patients with cancer were more extroverted and less neurotic than patients who did not have cancer. The results of the present study showed that the personality of patients with malignant tumors was slightly more extroverted and less neurotic than patients with nonmalignant tumors. Based on these results, we consider that this may reflect the desire of patients with malignant tumors to establish positive relationships with the people around them and to lead an ordinary life without fear and worry in order to suppress the fear of their illness and death.
There have been very few studies on the evaluation of lying tendencies (L-score) in patients with malignant tumors. Hahn et al. [18] reported that the L-score was high in patients with breast cancer. The results of the present study revealed that L-score was significantly higher in the $M$ group than in the non- $M$ group. It has been reported that persons with higher L-scores on MPI tend to maintain an ideal self image and express themselves through exhibitionism [19]. Based on the above, we suggest that patients with malignant tumors are motivated to present themselves as healthy to others and to adopt a mindset of conquering their cancer and seeking a quality of life higher than that imagined by their doctors.

The limitations of the present study include the fact that data were obtained using only MPI from just one investigation at a single facility, the short study period, the inclusion of relatively few patients with end-stage cancer, and the lack of investigation regarding cancer type or disease name, permorbid characters, past histories and educational levels in all subjects. Therefore, we plan to conduct further detailed investigations using personality inventories other than MPI and in other facilities, such as hospices.

\section{Conclusion}

Outpatients with malignant tumors showed a significantly higher L-score on MPI when compared with patients with non-malignant tumors. One reason for this may be that patients with malignant tumors are motivated to present an outward image of themselves as healthy and able to conquer their cancer. These results stress the importance of taking the mentality of patients with cancer into consideration when conducting treatment and care.

Table 4 Gender of patients and scores in malignant group ( $M$ group) and non-malignant group (non-M group)

\begin{tabular}{|c|c|c|c|c|c|c|}
\hline \multirow[t]{2}{*}{ Gender } & \multicolumn{3}{|c|}{$M$ group $(n=603)$} & \multicolumn{3}{|c|}{ Non-M group $(n=2400)$} \\
\hline & E-score & $\mathrm{N}$-score & L-score & E-score & $\mathrm{N}$-score & L-score \\
\hline Male & $27.4 \pm 11.9$ & $16.5 \pm 12.1$ & $17.4 \pm 6.9$ & $26.9 \pm 11.9$ & $17.3 \pm 11.0$ & $16.7 \pm 7.1$ \\
\hline Female & $27.8 \pm 11.2$ & $17.0 \pm 12.2$ & $17.8 \pm 7.3$ & $26.1 \pm 11.8$ & $18.0 \pm 12.2$ & $17.0 \pm 7.4$ \\
\hline
\end{tabular}

No significant differences between the two groups. 


\section{Disclosure of authors}

The manuscript submitted does not contain information about medical device(s)/drug(s). No funds were received in support of this work. No benefits in any form have been or will be received from a commercial party related directly to the subject of this manuscript. We certify that all applicable institutional and governmental regulations concerning the ethical use of human volunteers were followed during the course of this study.

\section{Competing interests}

The authors declare that they have no competing interests.

\section{Authors' contributions}

All authors read and approved the final manuscript.

Received: 12 June 2012 Accepted: 25 August 2012

Published: 11 September 2012

\section{References}

1. Nakaya N, Hansen PE, Schapiro IR, Eplov LF, Saito-Nakaya K, Uchitomi Y, Johansen C: Personality traits and cancer survival: a Danish cohort study. Br J Cancer 2006, 95:146-152.

2. Eysenck HJ: The respective importance of personality, cigarette-smoking and interaction effects for the genesis of cancer and coronary heart disease. Pers Individ Dif 1988, 9:453-464.

3. Arai S, Nakaya N, Kakizaki M, Ohmori-Matsuda K, Shimazu T, Kuriyama S, Fukao A, Tsuji I: Personality and gastric cancer screening attendance: a cross-sectional analysis from the Miyagi cohort study. J Epidemio/ 2009, 19:34-40.

4. Jensen AR: The maudsley personality inventory. Acta Psychol 1958, 14:314-325

5. Ooyama T, Komatsu R: Preparation and validation of Japanese Maudsley personality inventory. In New personality inventory-Maudsley personality inventory. 1st edition. Edited by Japanese MPI study group. Tokyo: Seishinsho; 1969:115-157. in Japanese.

6. Kasai Y, Takegami K, Uchida A: A study of patients with spinal disease using Maudsley personality inventory. Int Orthop 2004, 28:56-59.

7. Chida Y, Hamer M, Wardle J, Steptoe A: Do stress-related psychosocial factors contributeto cancer incidence and survival? Nat Clin Pract Oncol 2008, 5:466-475

8. Temoshok L, Heller B, Sagebiel RW, Blois MS, Sweet DM, DiClemente RJ, Gold ML: The relationship of psychosocial factors to prognostic indicators in cutaneous malignant melanoma. J Psychosom Res 1985, 29:139-153.

9. Schapiro IR, Ross-petersen L, Saelan H, Garde K, Olsen JH, Johansen C: Extroversion and neuroticism and the associated risk of cancer: a Danish cohort study. Am J Epidemiol 2001, 153:757-763.

10. Nakaya N, Tsubono Y, Hosokawa T, Nishino Y, Ohkubo T, Hozawa A, Shibuya D, Fukudo S, Fukao A, Tsuji I, Hisamichi S: Personality and the risk of cancer. J Natl Cancer Inst 2003, 95:799-805.

11. Hansen PE, Floderus B, Frederiksen K, Johansen C: Personality traits, health behavior, and risk for cancer: a prospective study of Swedish twin court. Cancer 2005, 103:1082-1091.

12. Garssen B, Goodkin K: On the role of immunological factors as mediators between psychosocial factors and cancer progression. Psychiatry Res 1999, 85:51-61.

13. Nakaya N, Tsubono Y, Nishino Y, Hosokawa T, Fukudo S, Shibuya D, Akizuki N, Yoshikawa E, Kobayakawa M, Fujimori M, Saiti-Nakaya K, Uchitomi Y, Tsuji I: Personality and cancer survival: the Miyagi cohort study. $\mathrm{Br} J$ Cancer 2005, 92:2089-2094.

14. Nakaya N, Bidstrup PE, Saito-Nakaya K, Frederiksen K, Koskenvuo M, Pukkala E, Kaprio J, Floderus B, Uchitomi Y, Johansen C: Personality traits and cancer risk and survival based on Finnish and Swedish registry data. Am J Epidemiol 2010, 172:377-385.

15. Yamaoka K, Shigehisa T, Ogoshi K, Haruyama K, Watanabe M, Hayashi F, Hayashi C: Health-related quality of life varies with personality types: a comparison among cancer patients, non-cancer patients and healthy individuals in a Japanese population. Qual Life Res 1998, 7:535-544.
16. Kissen DM, Eysenck HJ: Personality in male lung cancer patients. J Psychosom Res 1962, 6:123-127.

17. Coppen A, Metacalfe M: Cancer and extraversion. BMJ 1963, 2:18-19.

18. Hahn RC, Petitti DB: Minnesota Multiphasic personality inventrory-rated depression and the incidence of breast cancer. Cancer 1988, 61:845-848.

19. Morita A: Interpretation of each point in Japanese Maudsley personality inventor. In New personality inventory-Maudsley personality inventory. 1st edition. Edited by Japanese MPI study group. Tokyo: Seishinshobo; 1969:225-243. in Japanese.

doi:10.1186/1477-7819-10-187

Cite this article as: Wang et al:: Personality of outpatients with malignant tumors: a cross-sectional study. World Journal of Surgical Oncology 2012 10:187.

\section{Submit your next manuscript to BioMed Central and take full advantage of:}

- Convenient online submission

- Thorough peer review

- No space constraints or color figure charges

- Immediate publication on acceptance

- Inclusion in PubMed, CAS, Scopus and Google Scholar

- Research which is freely available for redistribution 